$831 \cdot 20$

Arquitectos:

ROBERTO GABETTI

AIMARO OREGLIA D'ISOLA

GIORGIO RAINERI
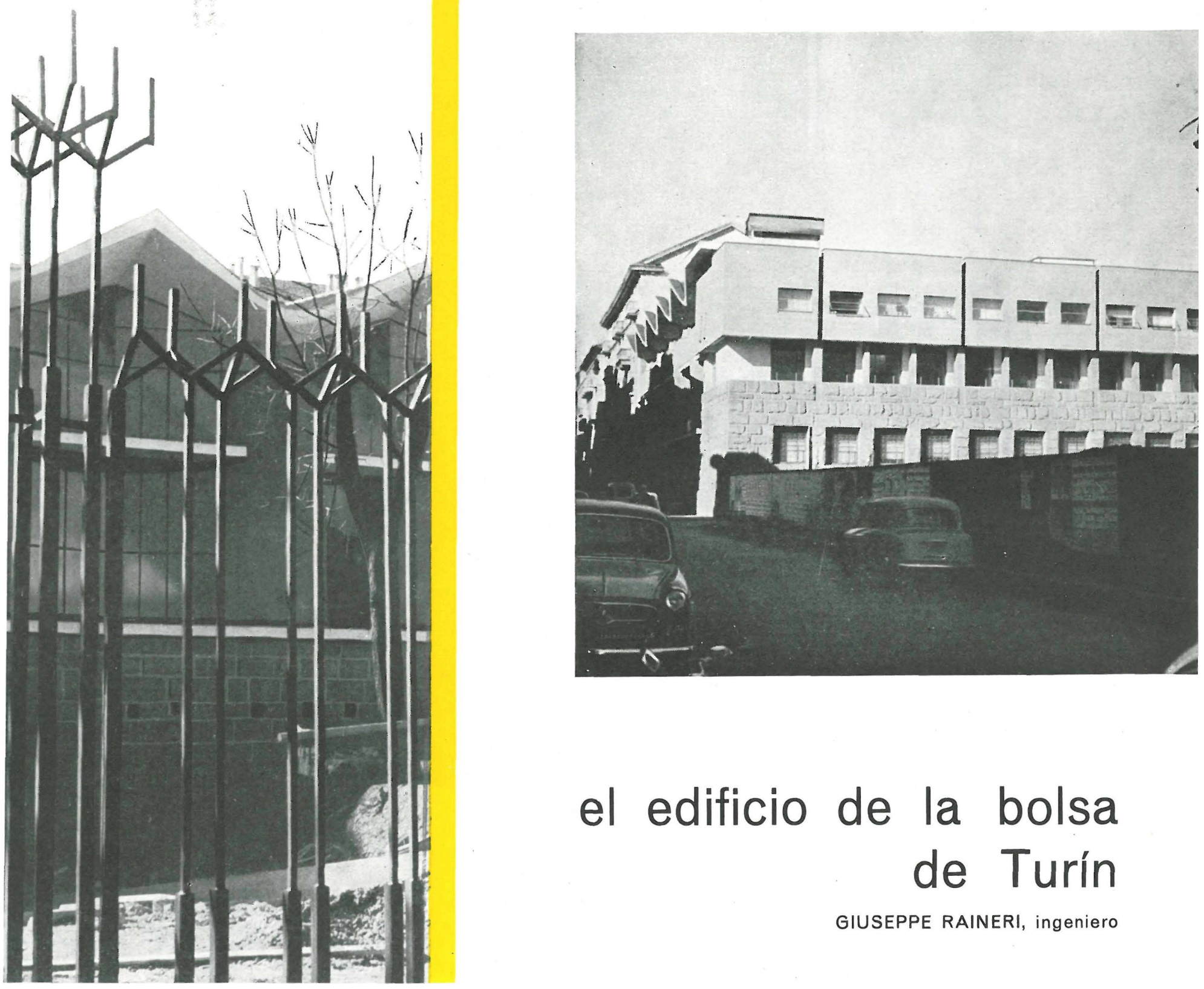

\title{
el edificio de la bolsa de Turín
}

GIUSEPPE RAINERI, ingeniero 


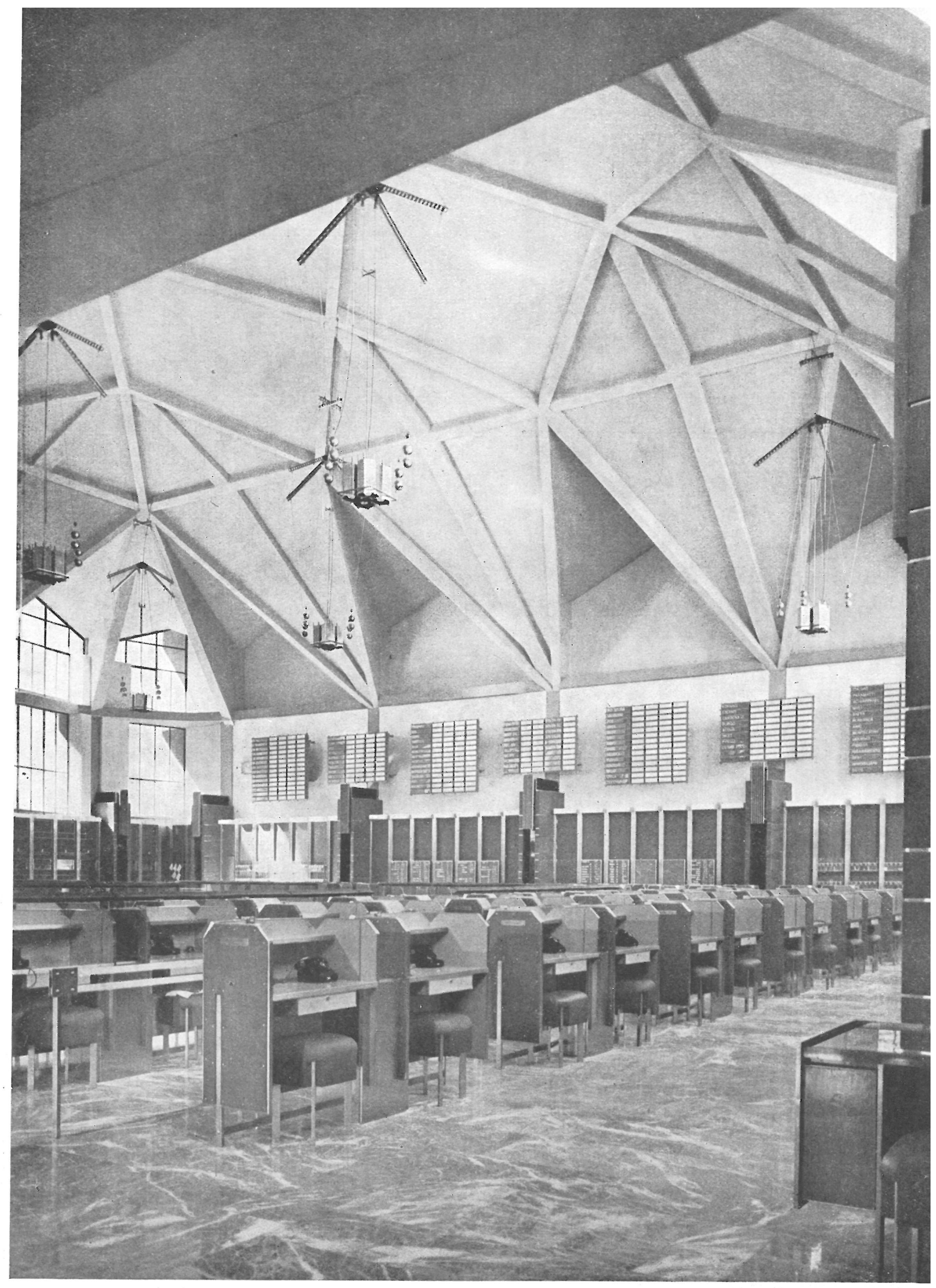

\section{interior}




\section{plantas}
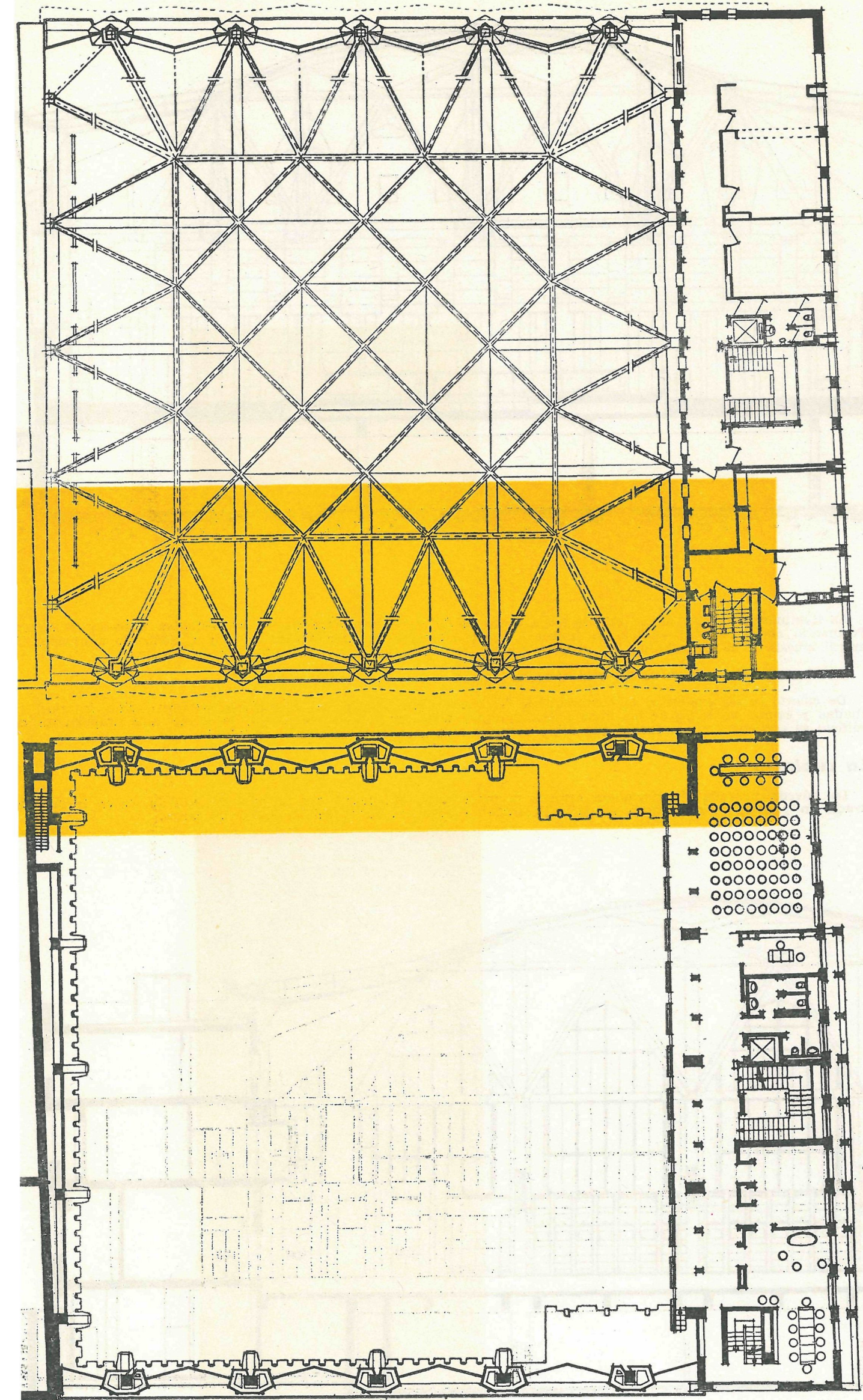

\section{Generalidades}

Como el edificio de la Bolsa de Valores de la ciudad de Turín, propiedad de la Cámara de Comercio, Industria y Agricultura de aquella ciudad, fué destruído durante la última guerra, se decidió su reconstrucción.

La obra de este edificio se sacó a un concurso. El inmueciu se halla en el centro de la to heterogéneo de edificanjunque según el plano de ordeneción segural plano de ordenaestá llamada a convertirse en jardines.

Como la función principal de 1a Bolsa se desarrolla casi completamente en una gran sala, en ella se ha concentrado el interés general. La gran sala de planta y de $38,5 \mathrm{~m}$ de lado.

El parquet o lugar destinado a los agentes que intervienen en la contratación rodea al corro, espacio central cuya función es la de registrar las operaciones. El corro esta formado por un recinto circular, con barandilla cuyo suelo se halla más bajo que el parquet.

El parquet se extiende en tres lados alrededor del corro, $y$ el espacio libre entre corro y parquet se ha separado por medio de barandillas, elevando ligeramente la cota del suelo respecto al parquet. El cuarto lado se ha reservado al público.

Dicho parquet está constitúdo por tres filas de mesitas formando cabina, adosadas en grupos de dos y provistas de teléfonos. Dos de estas tres filas se reșervan a los agentes, $y$ la tercera es para los representantes de los Bancos. Detrás de la última fila van las cabinas telefónicas, que son individuales y cerradas.

Sobre la pared opuesta al lugar reservado al publico se han instalado los cuadros luminosos que registran el movimiento de las cotizaciones.

Toda la actividad de la Bolsa se halla concentrada en el interior de la gran sala cuadrada, incluso la secretaría y presidencia, a cuyos departamentos se les ha delimitado con barandillas y un piso algo más elevado que el resto. 


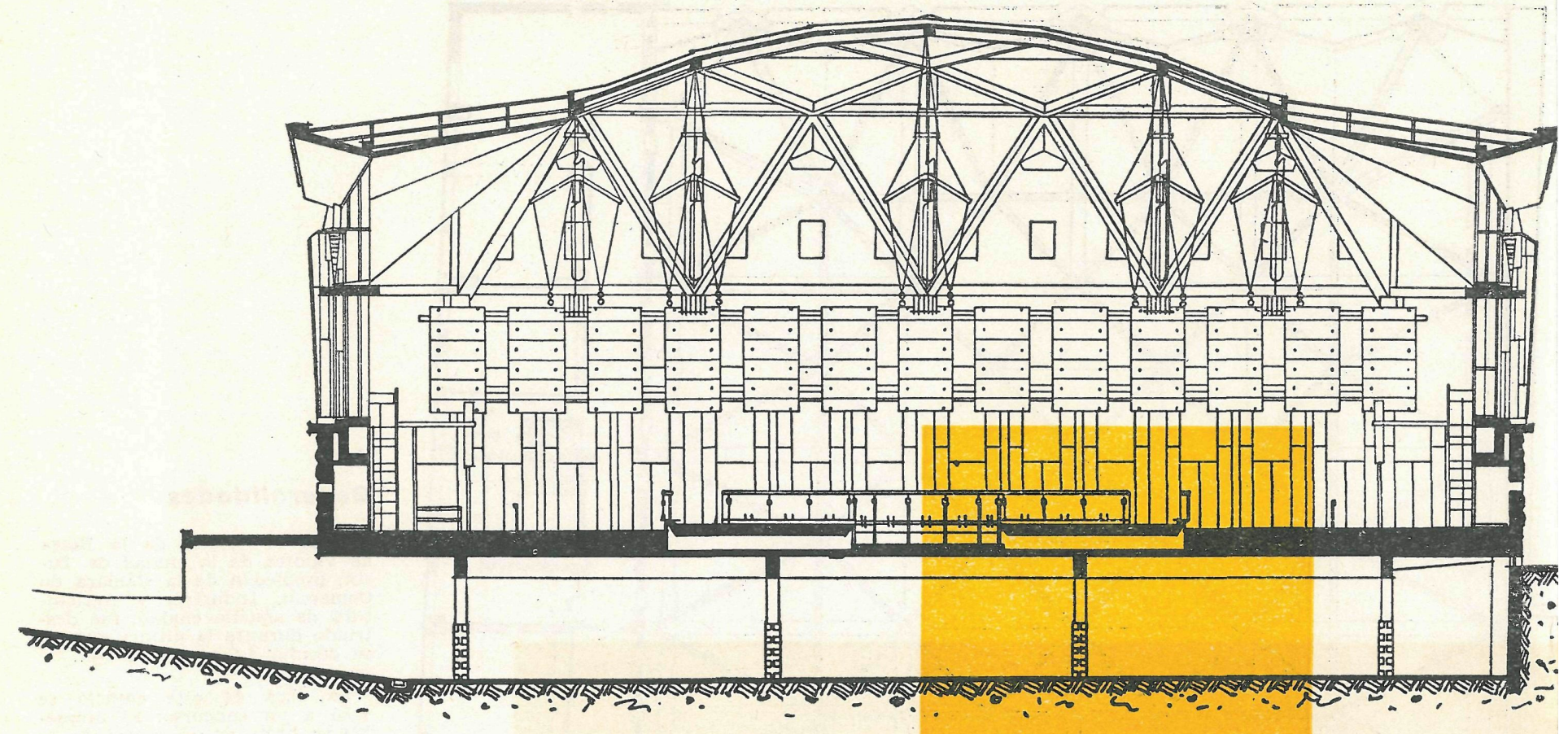

transversal

longitudinal
La iluminación natural de la sala se logra a través de ventanales vitrados de las fachadas noroeste y sureste Formando cuerpo con el edificio se levanta el departamento, de tres plantas y sótano, dedicado a oficinas. E muro opuesto a la fachada de las oficinas forma una medianería con las edificaciones vecinas.

En el sótano del edificio se ha habilitado un garaje.

De cuanto se ha expuesto, se comprenderá fácilmente que, aparte de la cuidada ornamentación interior, fa chadas y equipo moderno de las instalaciones propias a la función de la Bolsa, la parte más importante de edificio se concentró en la forma que debía cubrirse esta gran sala cuadrada en planta.

\section{La cubierta}

La bóveda nervada de hormigón armado y pretensado, que cubre la gran sala del edificio, es en forma cua drada en planta, cuya directriz se eleva ligeramente sobre la curva del funicular de carga.

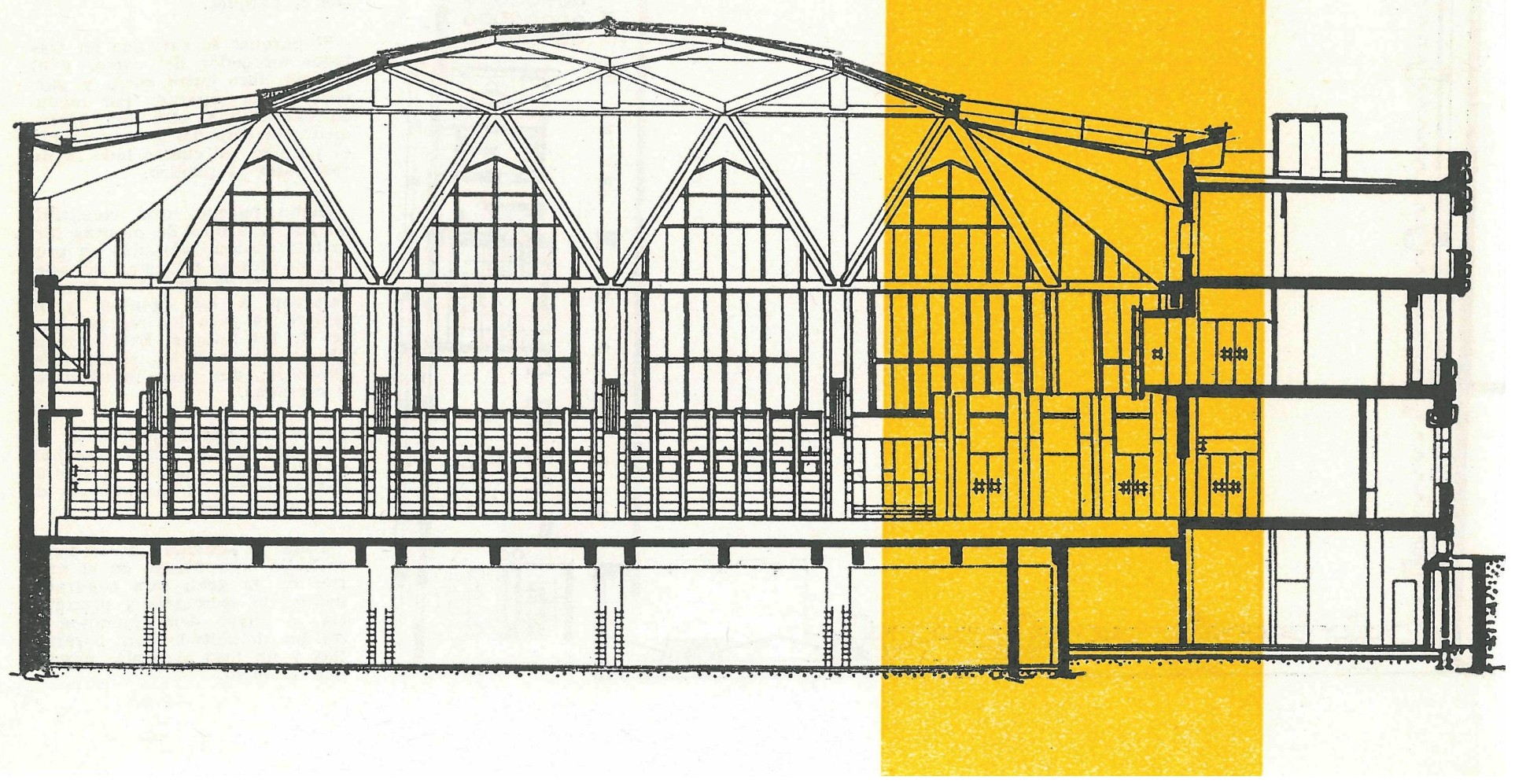



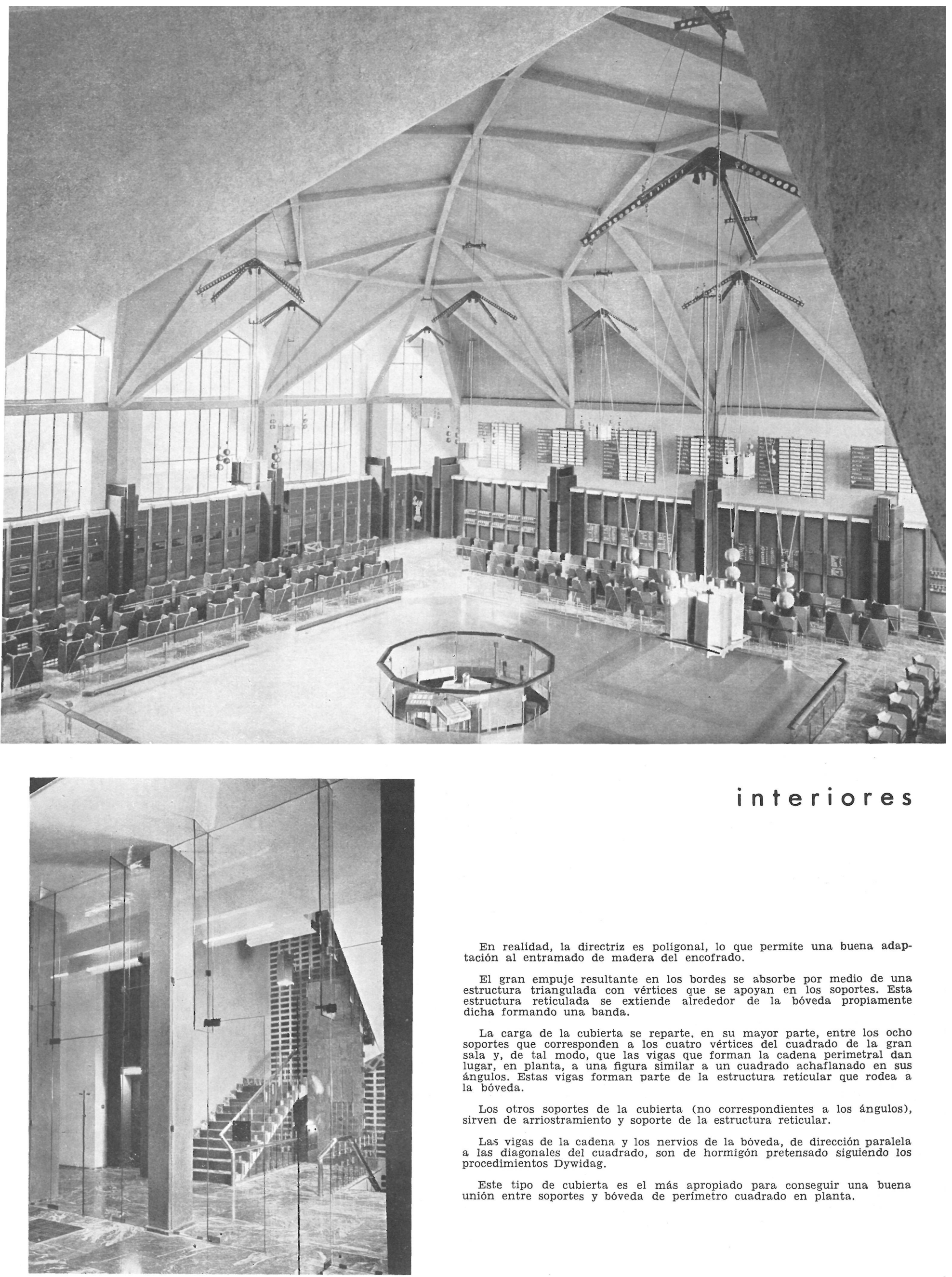

interiores 


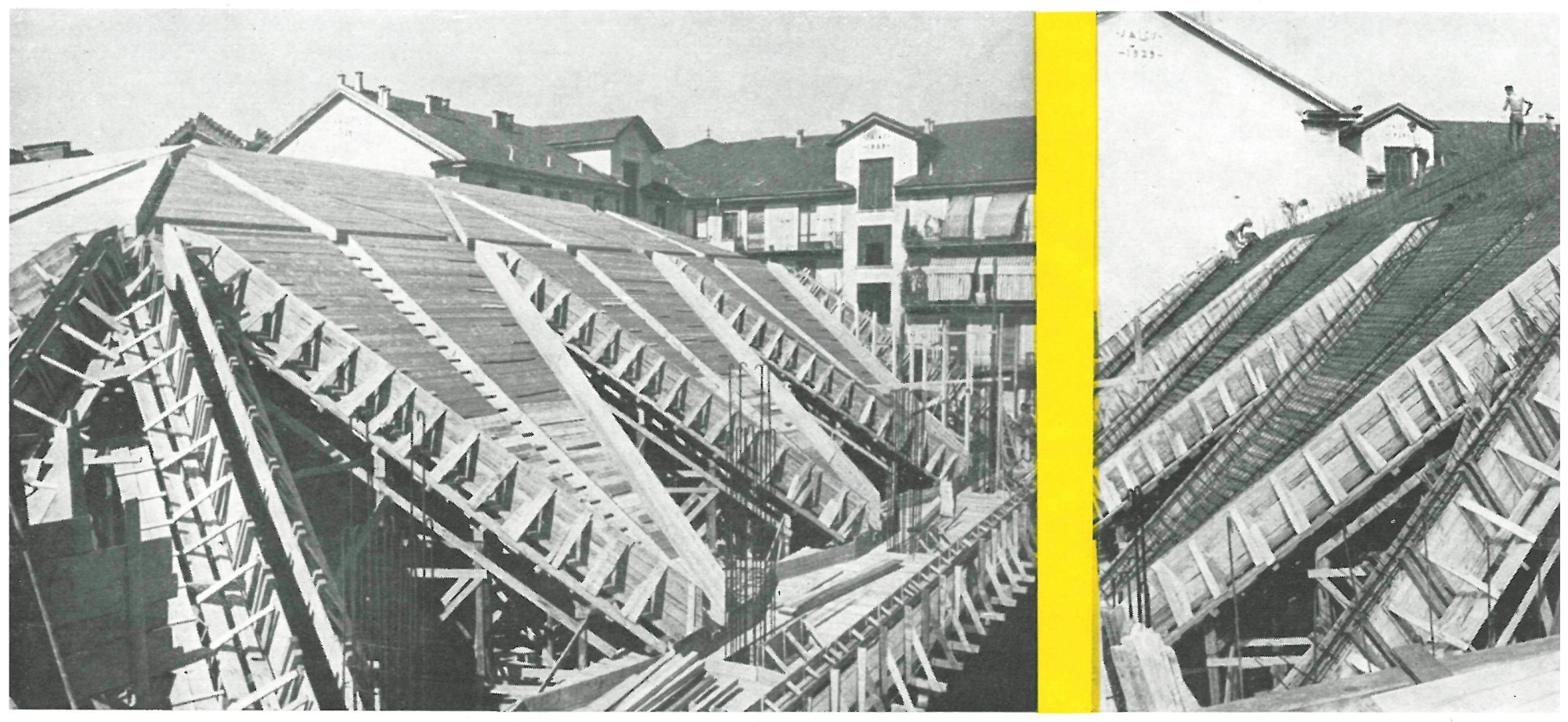

Los soportes se han espaciado a $7,70 \mathrm{~m}$, lo que da lugar a la formación de cuatro grandes ventanales en cada lado del cuadrado de las dos fachadas, mientras que, en cada una de las esquinas, el vano del ventanal que allí se forma es mitad del anterior. Con objeto de dar mayor iluminación natural cenital, los ventanales se han continuado en forma de luneto por encima de las vigas de cadena. Así, pues, los de las fachadas tienen ventanales continuos en altura y lunetos en la parte superior a partir de las vigas de cadena.

Los lunetos, de hormigón armado, que constituyen los ángulos o esquinas de la fachada se apoyan, en profundidad, sobre las vigas de arriostramiento de la estructura reticulada.

Los ventanales forman diedros entrantes, circunstancia de que se ha sacado partido por formar kalcones de tipo triangular.

La bóveda se ha cubierto con lámina de aluminio, de color verde claro. En la parte central, la chapa se ha fijado a listones de madera embebidos en la capa de perlita que aisla al hormigón. En la parte correspondiente a los lunetos perimetrales, la chapa de aluminio se fija a una serie de panecillos metálicos que se apoyan en la estructura reticular. Para aislar la parte de la bóveda de hormigón no protegida con perlita, se han empleado almohadillas de lana de cristal.

\section{Detalles del conjunto}

El cuerpo que constituye la acomodación para oficinas se ha separado de la estructura que constituye la cubierta por el intermedio de una junta de dilatación.

En la planta semisótano del cuerpo para oficinas se han instalado la central térmica, eléctrica y telefónica, así como también el guardarropas para los agentes de cambios y público. Esta planta está comunicada con el garaje del sótano.

El hall de entrada, formado por paños de cristal, se halla al mismo nivel que la gran sala, y dispone de una galería, también vitrada, al lado de la cual se encuentra un guardarropa, una oficina, saloncito, departamento telegráfico y gabinete del presidente. Al lado del hall de entrada se ha instalado un bar, que da al jardín y que funciona independientemente de la Bolsa.

En la primera planta del cuerpo de oficinas se halla el salón de reuniones, en comunicación con una gran galería vitrada y extendiéndose a todo lo largo de la fachada de este cuerpo y formando voladizo.

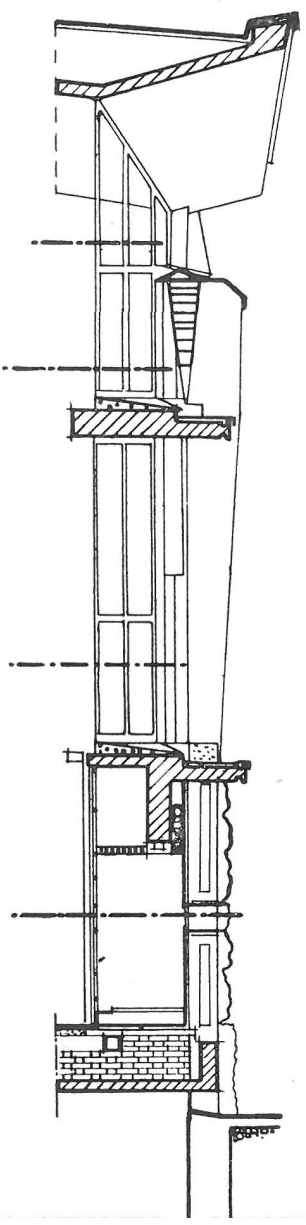

$\frac{\frac{0}{c}}{\frac{1}{0}}$

$\frac{c}{0}$ 


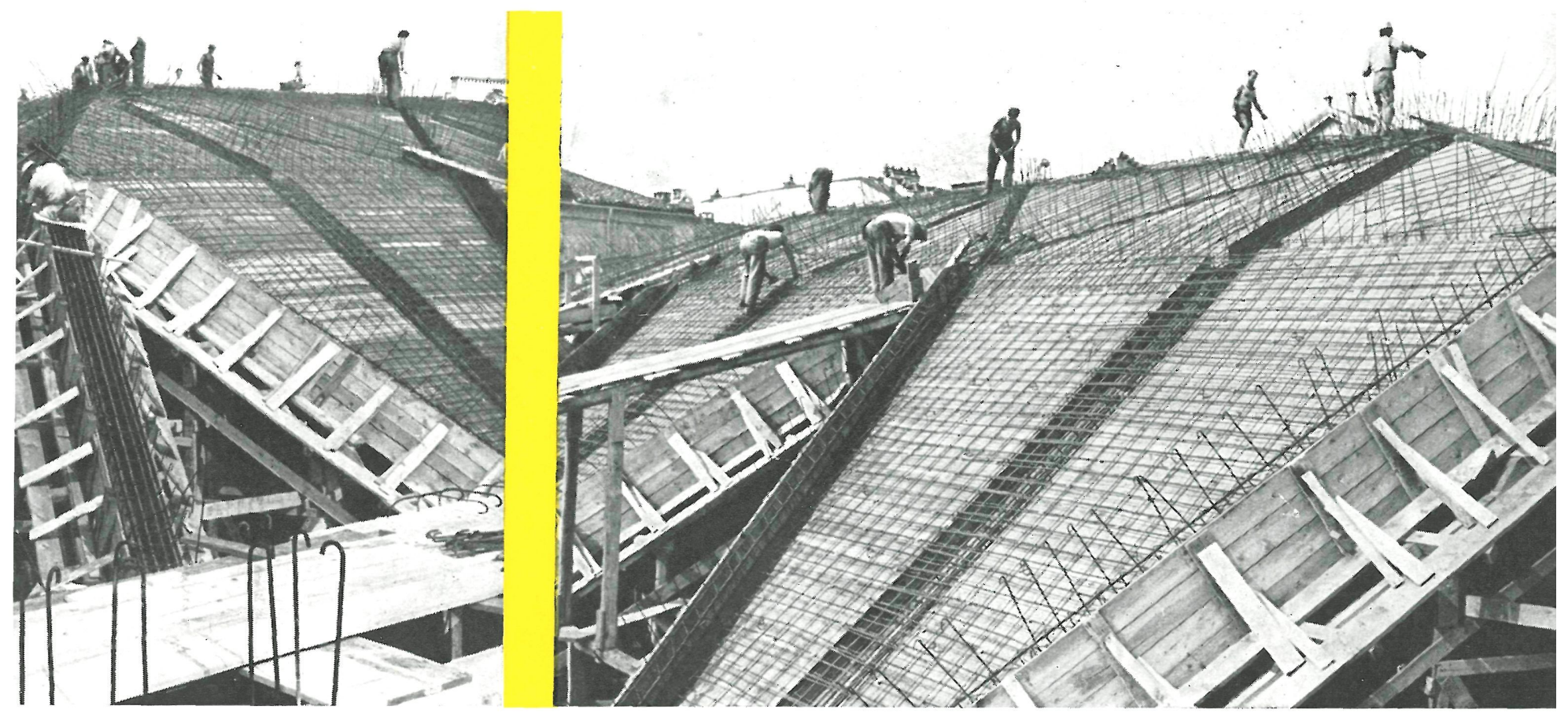

La última planta se ha dedicado a los servicios de oficinas y custodia.

Al exterior, las tres fachadas llevan un zócalo de sillería almohadillada, de basalto, que enrasa con la cornisa correspondiente al forjado de la gran sala en dos fachadas, y tambien lo lleva en la tachada del cuerpo de oficinas hasta la primera planta. En la fachada de la sala se han abierto ventanas para las cabinas telefónicas, y en la parte de zócalo almohadillado de la fachada del ala de oficinas se ha dipuesto una serie de ventanas.

Los grandes exteriores de acceso son de granito de color rosado; las peanas, jambas y cabezales de las ventanas, asi como las paredes del atrio de entrada, son de

Los tabiques de distribución y puertas son de placas de vidrio templado Las paredes de la gran sala se han revocado con Terranova blanca.

Para acondicionar la sala acústicamente lo mejor posible, problema muy importante en este caso particular. se han fijado en el techo una serie de placas de amianto puro, utilizando una cola bituminosa como agente fijador. Este tipo de revestimiento acústico, particularmente absorbente para la baja frecuencia, ha sido sustituído por paneles de vitroflex, recubiertos con platifex, colocados clante de la galería de la primera pla des ruidos de alta frocuen primer los ruidos de estos dispositivos han permitido mantener n las diversas frecuencias, un grado limpio de audición dentro de los límites teóricamente asignados.

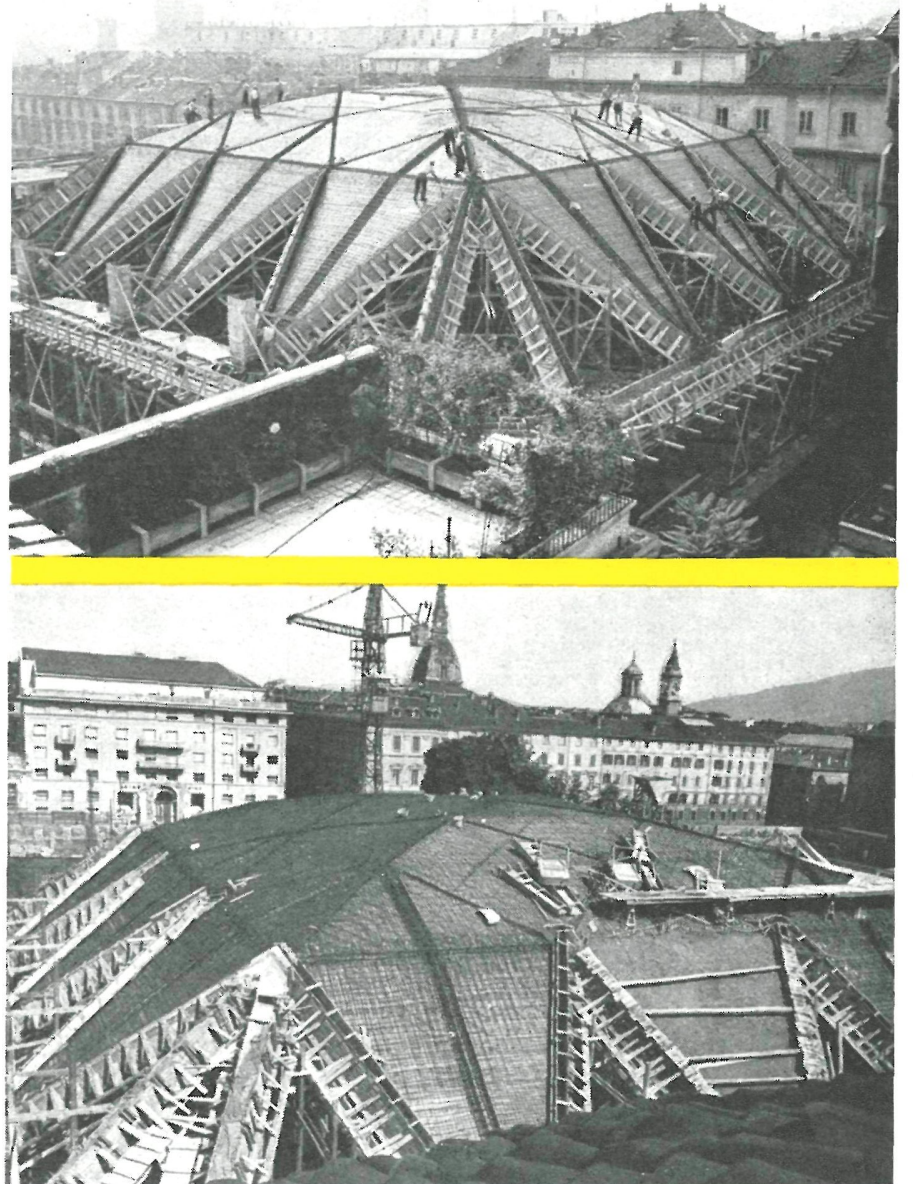




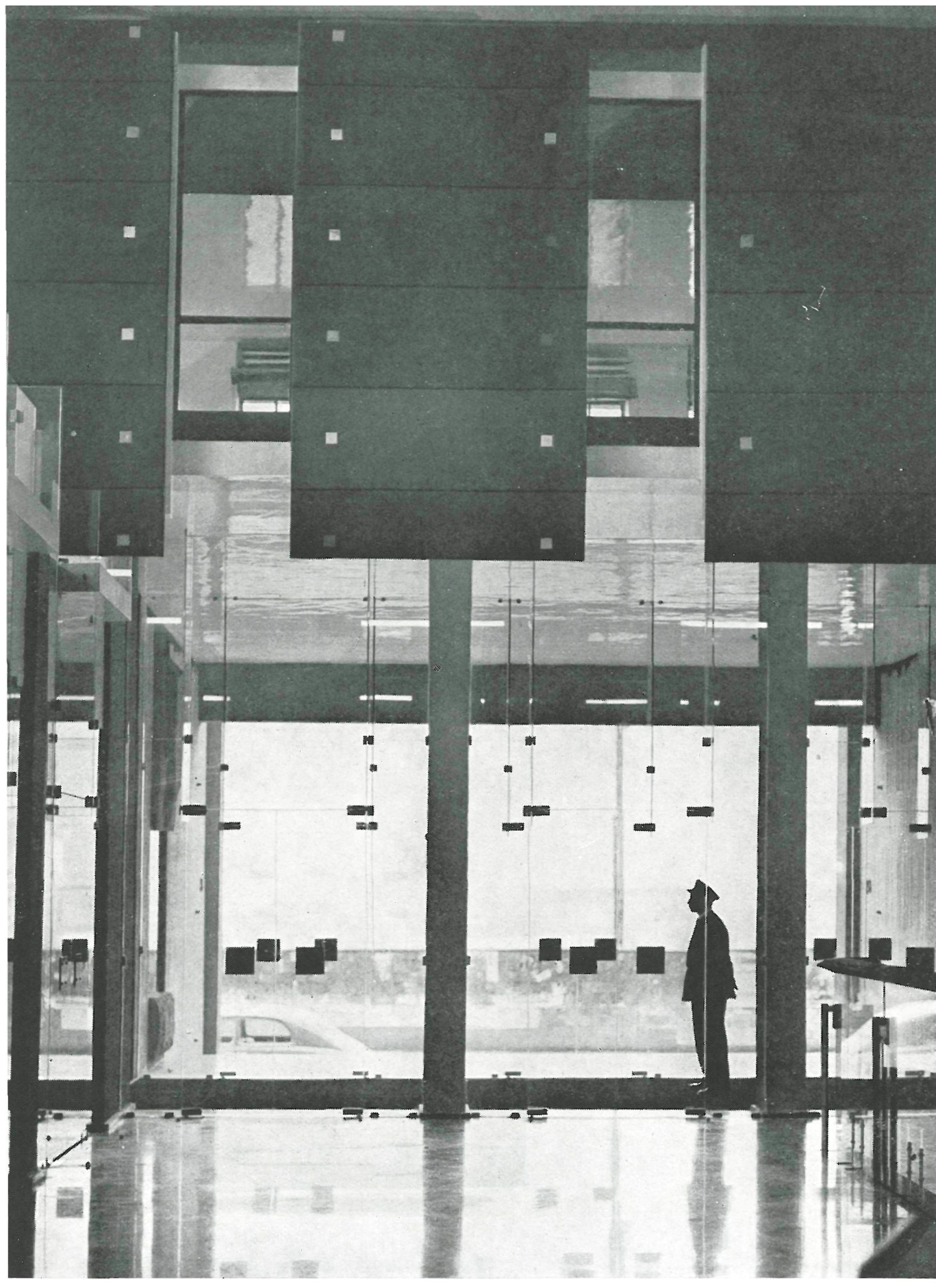

Fotos: MONCALVO e ITALFOTO

La iluminación artificial se ha conseguido con la instalación de nuevas lámparas metálicas, de contrapeso, cruceta fija superior y altura variable. Las lámparas propiamente dichas son bulbos fluorescentes.

Las instalaciones para la calefacción se componen de distintos circuitos independientes, cada uno de los cuales se adapta a su función y lugar. Así, en el garaje del sótano la calefacción se realiza por medio de unitermos; las oficinas, por medio de radiadores de agua caliente, y en la gran sala, parte más importante del edificio, el suelo se calienta con paneles radiantes, que aseguran el calor de fondo constante, calefacción que se complementa con una instalación de aire aconaicionado, pues as se puede caldear rápidamente la sala, dentro de un grado apropiado de humedad.

Las instalaciones telefónicas son muy complicadas, pues esta clase de explotaciones requieren un gran número de líneas directas y de interconexión.

Al garaje del sótano se accede por dos rampas; una de entrada y otra de salida, que se hallan en la parte del jardín.

J. J. U.

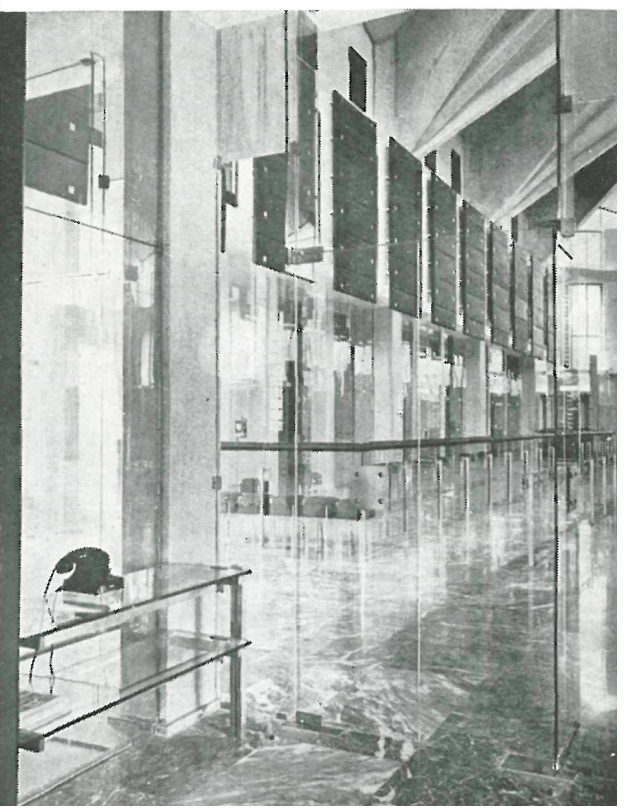

